"Volume 10, No. 1, Juni 2016"

\title{
MEMBANGUN FIQH EKOLOGI BERBASIS MASLAHAH
}

\author{
Oleh: \\ Rahwan \\ Akademi Perikanan Ibrahimy Situbondo \\ ach.rahwan@gmail.com
}

\begin{abstract}
Talking about the environment, it means talking about the environment around us, covering the entire ecosystem. Environment consists of flora and fauna, biotic and abiotic (and inanimate objects). Life environment are interdependent with each other. Human small part of the environment. This environment will determine the fate of human life. Will provide a conducive environment and secure quality of life, on the contrary, if the environment is less conducive it will result in insecure or lacking in quality even really threaten the safety of humans and the entire ecosystem in the world. Fiqh as Islamic law governing the pattern of human relationships with God and neighbor, and also discuss the human relationship with the environment. The share issue fiqh in an effort to maintain harmonious environment by providing rules or code of ethics of human relationships with the environment. As the ban on harming the environment and the obligation of preserving the environment. This environmental management is based to the proposition - proposition tipsily, namely al-Qur'an, al-Hadith, and the general principles of law legeslasi. When fiqh took part in preserving the environment, then the whole mukallaf particular awareness of environmental issues related to land, air and sea. So they have a high concern for the environment. Giving rights owned by the environment, such as the right to life and the right to expand, not plunder and exploit. With so environment remain stable, beautiful and conducive. Along with other human beings be peaceful. Based on the above views of researchers seeks to conduct research in matters of environmental jurisprudence. With the aim of formulating a comprehensive environmental fiqh, systematic, and akuntebel and can deal with the issue of global warming.
\end{abstract}

Key words: Fiqh, Lingkungan, Mashlahah.

\section{A. Pendahuluan}

Alam diciptakan oleh Allah dengan sistem hukum yang teratur ${ }^{1}$.

1 Dr. Zaglul Annajjar mengatakan, alam yang kita tempati ini sangat luas dan terbentang, merupakan bangunan yang solid, memiliki pergerakan yang teratur, dan 
Alam berjalan sesuai dengan sistem hukum yang telah di setting oleh Allah SWT Tak ada satupun unsur alam yang lepas dari hukum Allah. Sebab Dialah yang menggenggam dan mengawasi sistem itu. Sistem ini dikenal dengan istilah "sunnatullah" 2 . Masing-masing unsur alam memiliki hukum yang berbeda-beda. Antara unsur alam yang satu dengan lainnya.

Walaupun beda tata-aturnya memiliki hubungan dan ketergantungan yang cukup erat. Maka sudah menjadi keniscayaan jika ketimpangan hukum yang terjadi pada satu unsur alam berpengaruh besar pada yang lain. Dewasa ini, hampir semua negara tengah dihadapkan pada persoalan lingkungan hidup yang semakin hari menunjukkan gejala yang kurang baik. Ini terjadi karena lingkungan di sekitar kita secara berkelanjutan terus menerus mengalami kerusakan, di mana hal ini adalah ancaman besar terhada kelangsungan hidup umat manusia. Kerusakan alam telah menjelma menjadi malapetaka global yang menghantui semua mahluk.

Problem lingkungan yang terjadi saat ini bersifat massif, meliputi seluruh aspek lingkungan hidup. Misalkan pencemaran lingkungan (air, tanah, dan udara) yang dapat menimbulkan berbagai penyakit, yang diakibatkan oleh limbah industri rumah tangga atau asap kendaran bermotor. Persediaan air semakin langkah, baik secara kualitas maupun kuantitas, hutan-hutan juga mengalami nasib yang sama, eksploitasi besar-besaran terhadap hutan menyebabkan hutan tidak berfungsi lagi sebagai paru-paru dunia yang dapat menyerap karbon dan menyediakan

tertata rapi dalam setiap urusannya. Ia dibangun dengan satu cara mulai dari bagianbagiannya yang paling terkecil hingga yang paling besar. Alam ini terus berkembang. Jika kita lihat dari awal penciptaannya, maka pertama kali ia berupa suatu kesatuan materi yang besar/bola api dengan kerapatan tak terhingga, yang dinamakan "ledakan besar". Ledakan besar ini kemudian berubah menjadi asap, yaitu fase "asap", dan dari asap inilah diciptakan bumi, langit, bintang-bintang, planet dan benda-benda angkasa lainnya. Fase ini dinamakan fase "produksi". Kemudian jagat raya ini mulai menghimpun terhadap dirinya sendiri dan mengkristal menjadi satu benda/materi seperti bentuknya semula yang darinya dimulai penciptaan langit dan bumi. Fase ini dinamakan fase "pernyataan besar", yakni "the big crusl". Proses ledakan besar dan berubah menjadi asap pun terjadi lagi, dan diciptakan kembali bumi yang bukan bumi kita sekarang. Juga matahari tapi bukan matahari yang dulu menjadi atap kita dalam kehidupan dunia. Maka fase inipun akhirat dimulai. Setelah fase-fase terdahulu dilalui terjadilah fase " pelipatan atau penggulungan”. Dr. Ir. Ahmad Khalid Allam, dkk., lihat: Al-Qur'an Dalam Keseimbangan Alam Dan Kehidupan, Gema Insani, Cet, I, hlm. 243-244.

2 Sunnatullah adalah ketetapan Tuhan tentang aturan mahluk-mahluk ciptaannya mulai dari awal penciptaan sampai akhir hidupnya. Sunnatullah tidak akan berubah-ubah atau mengalami peralihan. Lihat; QS, al-Fathir:43.

$146 \mid$ JURNAL LISAN AL-HAL 
oksigen bagi kehidupan di muka ini. Namun demikian manusia tak juga menyadarinya. Bahwa alam telah murka pada manusia. Karena setiap saat alam di eksploitasi, hutan di tebang tanpa henti sampai gundul, belum lagi akibat kebakaran, lalu apa yang dapat kita andalkan sebagai cagar alam untuk melindungi ekosistem?.

Karena bengisnya bencana, banyak pemeluk agama yang goyah hati dan imannya. Ada yang berkata bahwa "tuhan telah murka terhadap manusia". Ada juga yang melontarkan bahwa "tuhan kejam dan tidak lagi mengasihi". Dia telah menyerahkan urusan manusia kepada setan setelah bosan melihat kedurhakaan manusia. Bahkan da yang berkata"memang ada dua tuhan, tuhan baik dan tuhan jahat, yang baik bijaksanan dan menciptakan kebaikan dan yang jahat yang berperanan dalam peristiwa bencana alam". ${ }^{3}$ Begitulah kurang lebih keluh kesah ungkapan rasa resah mendalam dan ketakutan manusia di saat bencana meluluh-lantakkan persada tercinta.

Kita sebagai umat yang beragama islam, hendaknya mempunyai keyakinan bahwa dibalik semua rentetan musibah/bencana ada hikmah yang sangat besar bagi manusia. Baik hikmah itu dirasakan langsung oleh manusia ataupun tidak. Kata bijak menyindir, "Kullu Syaiin layakhlu min hikmatin" (pada setiap sesuatu yang kita tidak senangi pasti terkandung hikmah yang tak terhingga).

Dalam islam bencana dengan arti musibah yang ditimpakan oleh Allah kepada hambanya memiliki tujuan. Paling tidak ada tiga tujuan yang sangat prinsipil. Pertama bencana sebagai cobaan. Allah akan memberikan cobaan kepada hambanya guna untuk mengetahui kualitas keimanan dan membedakan antara hamba yang taat sejati dan yang taat karena manusia atau lainnya. Sebab boleh jadi ia menjadi orang yang taat pada perintah Allah (melaksanakan perintah dan menjahui larangann-Nya) di saat lapang. Namun pada saat ia dalam kesempitan baju ketaatannya (iman wa taqwa) lambat laun ia tinggalkan. Pada saat inilah baru dijumpai mana yang benar-benar taat sesungguhnya, dan mana yang taat sebatas ikutikutan atau lainnya.

Kedua, bencana sebagai ujian ${ }^{4}$. Biasanya bencana ini diturunkan

${ }^{3}$ M. Quraisy Shihab, Menabur pesan Ilahi, Mizan, Bandung, 2005.

4 QS. Al-Baqarah (2): 155. Artinya : "dan sesungguhnya akan kami berikan ujian kepadamu, dengan sedikit ketakutan, kelaparan, kekurangan harta, jiwa dan buah-buahan. Dan berikanlah berita gembira kepada orang-orang yang sabar." Ujian tidak hanya berupa kesusahan dan kesulitan, bisa juga berupa kesenangan seperti yang dianugerahkan kepad Nabi Sulaiman aneka kekuasaan dan kenikmatan. Namun beliau menyadari fungsi nikmat sebagai ujian. 
oleh Allah kepada hamba-hambanya yang dicintai. Yaitu; para Rasul Nabi, sahabat, Mujahidin (yang berjuang dijalan Allah), shalihin (orang beramal shaleh), muttaqin (orang yang taqwa) dan seterusnya. Contoh kecil Nabi Ayyub diuji oleh Allah dengan penyakit kulit kronis. Seluruh tubuhnya dimakan ulat kecuali hati beliau yang tidak terjemahnya. Ini karena permintaan beliau kepada Allah. Sebab kalau hati dimakan oleh ulat, beliau khawatir tidak bisa lagi berdzikir kepada Allah setiap saat. Nabi Ayyub menghadapi ujian itu dengan penuh kesabaran dan kesadaran. Karena beliau dimasukkan oleh Allah pada golongan orang-orang penyabar ('ulul azmy). ${ }^{5}$

Ketiga, bencana sebagai adzab (siksa). Ini berlaku untuk hambahamba Allah yang durhaka. Hamba yang tidak mau mendengarkan ayatayat Allah dan juga tidak mau melihat tanda-hubungan, baik kepada Allah maupun kepada sesamanyaatau alam sekitarnya (hablum mina Allah wa hablum mina annas) akan melanda tidak hanya kepada orang yang melakukan kedhaliman dan kemaksiatan saja. Namun bencana juga akan menggoncang orang-orang shaleh yang berdampingan dengan si dhalim. ${ }^{6}$ Allah telah mewanti-wanti dalam al-Qur'an kepada manusia agar senantiasa takut kepada bencana yang akan ditimpakan oleh Allah.

Menurut kacamata agama dan moral, bencana alam terjadi karena manusia lupa terhadap tuhannya. Kemaksiatan merajalela dimana-mana, moralitas telah hancur berantakan. Kedhaliman telah melampaui batas kewajaran, pertumpahan darah menambah jumlah korban bencana alam. Masalah lingkungan dan cuaca global saat ini menjadi tema sentral perbincangan ilmuan modern internasional. Terbukti pada konfrensi internasional tentang perubahan iklim di Bali, 3 - 14 Desember 2007. Mereka dengan serius dan intent membahas masalah pemanasan global yang berbahaya terhadap ekosistem dan ekologis. ${ }^{7}$ Sebab bumi harus diselamatkan dari ancaman global. Sebab pada realitanya manusianya masih belum memiliki kesadaran yang kuat terhadap pelestarian

5 Ulul 'Azmy adalah para Rasul yang sabar dan mempunyai keteguhan hati (kometmen) dalam menghadapi rintangan dan tantangan saat menyebarkan risalah Allah dalam dakwahnya. Lihat QS. Al-Ahqaf (46): 35. Menurut sebagian pendapat para Rasul yang masuk golongan "ulul al-azmy" ada lima, yaitu ; Nabi Ibrahim, Nabi Nuh, Nabi Isa, Nabi Musa, dan Nabi Muhammad SAW. Sebagian pendapat memasukkan Nabi Ayyub dalam golongan ini karena kesabaran beliau dalam menghadapi ujian penyakit dari Allah.

6 Dalam firmannya Allah memperingatkan kepada manusia, "Dan peliharalah dirimi dari pada siksaan yang tidak khusus menimpa orang-orang lalim saja di antara kamu. Dan ketahuilah bahwa Allah amat keras siksaan-Nya. "QS. Al-Anfal (8); 25.

7 Majalah Sosiality, edisi 3, hlm. 10.

$148 \mid$ JURNAL LISAN AL-HAL 
lingkungan yang kondusif. Di saat kejadian bencana yang senantiasa memurak-porandakan persada ini, seluruh umat manusia menjadi bingung. Disamping mereka mencari tahu kenapa ini terjadi. Takdir ataukah lainnya?. Bagi mereka yang kurang berpendidikan pasti mengatakan ini takdir tuhan atau karena kekuatan miistik yang lain. Tapi bagi para ilmuan akan terus mencari jawaban yang memuaskan. Tak terkecuali para ulama, mereka kembali mengkaji kembali tafsir-tafsir alQur'an yang menjelaskan tentang masalah bencana

Wal-hasil, memang masalah lingkungan telah disinggung dalam literatur fiqh ${ }^{8}$ dan tafsir - tafsir ulama klasik. Tapi hanya sebatas konsepsinya saja. Fiqh islam seakan hanya berkutat dalam persoalan ubudiyah (ibadah), mu'amalah (transaksi), Munakahat (perkawinan), dan jinayat (tindak pidana). Akibatnya islam terkesan kurang peduli atau kurang ramah terhadap stabilitas lingkungan hidup. Hal ini besar kemungkinan persoalan lingkungan belum pernah mendapat perhatian yang serius dari para mujtahid. Sebab persoalan lingkungan tidak sekomplek sekarang ini. Memang kita akui bahwa al-Qur'an dan hadist sebagai sumber ilmu islam pertama, bukan ilmu pengetahuan. Diharapkan bisa membahas tuntas persoalan-persoalan yang terjadi di dunia ini secara mendetil. Apalagi masalah ilmu alamdan teknologi (termasuk didalamnya juga masalah lingkungan hidup). Tapi pada hakekatnya al-Qur'an dan alhadist tidak menghambat perkembangan ilmu pengetahuan. ${ }^{9}$ Kita jumpai di beberapa tempat ayat al-Qur'an dan al-hadist mendorong manusia agar terus menggali ilmu pengetahuan agar menemukan kebenarannya. ${ }^{10}$ Bahkan prinsip-perinsip umum tentang ilmu pengetahuan telah

8 Fiqh: ilmu yang membahas tentang hukum-hukum islam (syari'ah) praktis yang diambil dari dalil-dalil yang rinci (tafsily), Abdul Wahb Khalaf, Ilmu Usul Fiqh, (Berut; 1978), hlm. 12.

9 Al-Qur'an mendukung perkembangan ilmu dan teknologi bahkan memberikan dasar - dasarnya untuk kemudian dijadikan pijakan penelitian. Tapi al-Qur'an juga mendambakan kelestarian lingkungan hidup. Teknologi boleh berkembang pesat, dan lingkungan hidup tetap lestari. Pandangan ini dikenal dengan pandangan meta-sosial sistem, lihat: Mujiono Abdillah, Agama Ramah Lingkungan Persepektif Al-Qur'an, (Paramadina, Jakarta, 2001), hlm. 127.

10 Kitab suci al-Qur'an memotivasi untuk memikirka ayat-ayatnya, sebagaimana yang termaktub dalam surah shad (38); 29; ulul albab adalah orang-orang yang memiliki akal murni yang tidak diselubungi oleh "kulit" yakn kabut ide yang dapat melahirkan kerancuan dalam berfikir. Berkah didalam makna -makna yang dikandungnya, karena alQur'an adalah sumber yang tak kering, sehingga betapapun di tafsirkan selalu saja ada makna baru yang belum terungkap sebelumnya. M. Quraish Shihab, Tafsir Al-Misbah, (Jakarta: Lentera Hati, 2005), Vol. 12, 138. 
dipampangkan oleh al-Qur'an, demikian juga ilmu pengetahuan dan penemuan ilmiah tidak bertentangan dengan al-Qur'an. ${ }^{11}$

Namun demikian, memelihara (amal shaleh) lingkungan bahkan jauh lebih penting ketimbang amal shaleh terhadap lainnya, betapapun seseorang memeliharahubungan baik kepada Allah dan sesamanya, namun ia tidak ramah lingkungan, ia bukan termasuk orang yang mukmin. Sebab tujuan agama (maqasid asy-syariah) ${ }^{12}$ berupa pelestarian lingkungan hidup tidak di indahkan. Jika lingkungan menjadi rusak, maka mustail bisa terwujud suatu kemaslahatan agama (diny) dan manusia (nasy). Sebab stabilitas ekologi yang kondusif menjadi penentu dari kemaslahatan yang lainnya.

Kepedulian islam . ${ }^{13}$ terhadap harmoni linkungan hidup, bisa dilihat dalam al-Qur'an dan al-Hadist. Dalam hadist kebersihan dihubungkan dengan sesuatu yang sangat esensial yaitu iman. ${ }^{14}$ Orang yang beriman tentu akan selalu menjaga kebersihan lingkungan (darat, laut, dan udara). Jika kebersihan lingkungan bisa terjaga maka akan tercipta suasana yang sejuk dan menyenangkan. Udara dan air bebas polusi, dan lingkungan tanpak asri. Penghuni bumi pasti akan sehat.

Disamping itu juga al-Qur'an mengutuk orang-orang yang berbuat kerusakan di muka bumi (tufsiduna fil-ard). ${ }^{15}$ Al-Qur'an menganjurkan kepada manusia agar senantiasa berbuat kebaikan (amalu ash-shaleh) baik kepada sesama, binatang maupunlingkungan hidup. Dunia diciptakan oleh Allah beserta sistemnya yang teratur diperuntukkan kepada kemaslahatan manusia. Darat dan laut ditundukkan oleh Allah agar manusia bisa memanfaatkannya. Namun demikian manusia tidak boleh serta-merta mengeruk kekayaan alm tanpa batas. Sebab jika kekayaan alam terus dieksploitasi tanpa henti maka akan kehilangan keseimbangan. Akibatnya alam tidak lagi bisa memberi manfaat bagi manusia, bahkan justru sebaliknya. Alam akan menyuguhkan malapetaka.

11 Ibid, hlm. 27.

12 Maqasid asy-Syariah dimaksud adalah hifdhu ad-din(memelihara agama), hifdhu an-nafs (memelihara jiwa) hifdhu al-aql (menjaga akal), hifdhu al-mal (menjaga harta), hifdhu an-nasl (menjaga keturunan). Lihat: Dr. Wahbah az-Zahaily, Usul al-Fiqh al-Islamy, Juz, II.

13 Islam ialah agama yang di bawa oleh Nabi Muhammad SAW. Yang bertujuan untuk menyelamatkan manusia baik di dunia ('ajal) maupun di akhirat (ajal)

14 Dalam hadist dijelaskan, "kebersihan bagian dari iman". Berarti jika seseorang tidak menjaga kebersihan keimanannya tidak sempurna.

15 Lihat QS. Al-Qashash (77), al-Baqarah: (11) dan al-A'raf: (55 \& 84). Dalam ayat ini Allah mengutuk orang-orang yang berbuat kerusakan di muka bumi. Sebab Allah telah memperbaikinya dan mengaturnya dengan baik dan bijaksana.

$150 \mid$ JURNAL LISAN AL-HAL 
Untuk itu Allah menciptakan manusia di muka bumi ini disamping agar ia menyembah kepada-Nya, juga sebagai penganti Allah (khalifah Allah fil-ard). ${ }^{16}$ Dalam arti manusia diberi wewenang oleh Allah untuk mengelola, mengatur dan memanfaatkan (isti'mar fi al-ard). ${ }^{17}$ Sumber daya alam (SDA) sesuai dengan kebutuhannya. Tidak sampai melampaui batas kewajaran. Allah tidak menyukai orang-orang yang melampaui batas.

Dari paparan di atas pada hakekatnya islam agama yang sangat peduli dan ramah terhadap ekologi (al-biah). Tapi sampai saat ini masih belum ada satu formulasi konkrit dan sistematis secara tematik (maudhu'ie) membahas masalah lingkungan. Padahal masalah kelestarian lingkungan merupakan kebutuhan utama yang tidak bisa ditawar lagi. Tujuannya tak lain demi kelangsungan mahluk hidup (manusia) di dunia.

Tanpa pelestarian dan penjagaan terhadap keseimbangan alam semesta, mustail kita bisa menjaga kepentingan-kepentingan lain yang selama ini dianggap sangat urgen. Sepeti, hifdzu ad-din (menjaga agama), hifdzu an-nafs (menjaga jiwa), hifdzu al-'aql (menjaga akal), hifdzul biah (menjaga keseimbangan lingkungan) kami anggap sebagai sentral dari semua itu.

Dari itu kami bermaksud mengangkat masalah fiqh lingkungan (fiqh al-biah), guna menformulasikan kehendak al-Qur'an dan al-Hadist (muradu asy-Syari'e) dalam pelestarian harmonisasi linngkungan hidup "berbasis maslahah".18 Sehingga islam sebagai agama rahmat bagi alam

16 QS: Al-Baqarah: 30. Artinya; "sesungguhnya aku akan menjadikan khalifah (Adam) dimuka bumi."

17 QS: Hud (11): 61. "Dia telah menciptakan kamu dari bumi (tanah) dan menjadikan kamu sebagai pemakmurnya". Maksudnya manusia dijadikan penghuni bumi untuk menguasahi dan memakmurkannya.

18 Tujuan Islam disyariatkan adalah menarik suatu maslahah dan menghindar dari kerusakan "jalb al-mashaleh wa daru al-mafasid". Di tinjau dari segi orgensitasnya mashlahah ada tiga tingkatan yaitu: 1. Daruriyat (primer), yaitu kepentingan pokok manusia yang harus dipenuhi untuk menegakkan kemashlahatannya, jika ia tidak ada maka sistem kehidupan akan rusak dan mashlahah tidak akan terpenuhi serta kerusakan umum : (menjaga jiwa), hifdzu al-'aql (menjaga akal), hifdzu al-'irdhi (menjaga nama baik), dan hifdzu al-mal (menjaga harta benda). 2. Hajiyat (sekunder), yaitu: kepentingan manusia untuk memperoleh kemudahan dan kelapangan, dan bisa menanggung beratnya. Jika kepentingan ini tidak terpenuhi, maka tidak berakibat fatal terhadap rusaknya sistem kehidupan dan kerusakan tidak akan menyebar luas, akan tetapi ia akan merasa kesulitan dan tidak mendapatkan kelapangan. 3. Tasiniyat (tersier). Kepentingan yang menjadi tuntutan kebaikan (muruah), tatakrama dan keindahan. Jika kepentingan ini tak terpenuhi tidak berakibat fatal terhadap rusaknya sistem kehidupan. Lihat: Dr. Jamaluddin 'Athiyah, Nafwa Tafilu Al-Maqasid asy-syari'ah, Darul Fikr, Damaskus-Suryah, 
semesta dapat kita buktikan dengan kongkrit. Dan tidak ada keraguan laig bahwa islam agama yang benar-benar kaffah (menyeluruh), peduli dan ramah terhadap lingkungan hidup.

\section{B. Pembahasan}

\section{Konsepsi Harmonisasi Lingkungan Dalam Fiqh}

Fiqh sebagai hukum praktis yang berhubungan dengan perbuatan manusia, tidak hanya membahas seputar ubudiyah dan muamalah manusia, fiqh juga bicara tentang masalah-masalah yang berhubungan dengan lingkungan hidup. Bahkan sejak awal, fiqh telah memproklamirkan diri sebagai disiplin ilmu yang ramah lingkunagn hidup.

\section{Fiqh, Antara Teknologi dan Lingkungan}

Fiqh tidak melarang laju perkembangan teknologi dan sains. Teknologi memang seharusnya terus berkembang seiring dengan perkembangan ilmu pengetahuan, riset dan eksprimen yang dilakukan manusia. Teknologi adalah buah dari ilmu pengetahuan yang bermanfaat besar untuk efektifitas dan efisiensi dalam memenuhi hajat hidup manusia.

Tapi perkembangan teknologi tidak boleh melampaui batas-batas aturan hidup. Teknologi tetap harus tunduk dibawah aturan hukum, sebab kalau teknologi berjalan sendiri tanpa peduli terhadap aturan hidup, akan berbahaya pada keselamatan kehidupan dunia. Teknologi dan fiqh, khususnya fiqh lingkungan harus sinergis dan saling menyempurnakan. Tidak boleh saling berpisah apalagi saling bermusuhan.

\section{Prinsip-prinsip dalam upaya membangun fiqh lingkungan}

Fiqh sebagai disiplin ilmu yang peduli terhadap lingkungan, dalam literatur fiqh ditemukan berserakan dibeberapa bab dan pasal. Sekarang akan coba peneliti analisa konsepsi-konsepsi itu. Tujuannya agar ada titik terang dan penyempurnaan dalam perumusan fiqh lingkungan.

Di dalam pembahasan ini prinsip-prinsip fiqh lingkungan hanya ada enam macam, yaitu meliputi: prinsip perlindungan jiwa, prinsip kehidupan dunia bukan tujuan, prinsip produksi dan konsumsi standar kebutuhan, prinsip keselarasan dan keseimbangan alam mutlak ditegakkan, prinsip semua mahluk muhtaram, prinsip manusia sebagai pelaku moral dalam menjaga kelestarian lingkungan. Prinsip ini perlu ditambah agar lebih

Juli 2001, hal: 72 dan Abdul Wahab Khallaf, Opcit, hlm. 200-201.

$152 \mid$ JURNAL LISAN AL-HAL 
sempurna paling tidak dengan empat prinsip yaitu; prinsip kasih sayang (ar-rahmah) prinsip keadilan (al-'adalah), demokrasi dan prinsip integritas moral. Prinsip ini sangat penting sekali kita masukkan dalam prinsip-prinsip fiqh lingkungan guna menunjang kesempurnaan sebuah teori.

a. Prinsip Kasih Sayang (ar-rahmah)

Islam sangat identik dengan agama kasih sayang. Agama ini di syari'atkan Allah untuk menebarkan kasih sayang bagi alam semesta. Kasih sayang bagian dari sifat-sifat Allah. Tuhan dikatakan dzat yang maha pengasih lagi maha penyayang terhadap mahluk ciptaannya. Kasih sayang ini dapat menjaga kehidupan seluruh mahluk dalam kebaikan dan kesempurnaan.

Rasa kasih sayang ini hak semua mahluk Allah. Tidak hanya manusia yang berhak mendapatkannya.Memberikan hak kasih sayang terhadap seluruh ekosistem, baik yang terdiri dari biotik maupun abiotik, merupakan upaya untuk melestarikan kehidupan lingkungan. Maka hidup dan kehidupan manusia akan tentram, damai dan tanpa ada rasa ketakutanakan bencana alam.

b. Prinsip Keadilan (al'adalah).

Keadilan mutlak ditegakkan demi terbangunnya tatanan yang berkeadilan, Baik dalam tatanan sosial maupun ekologi. Penerapan keadilan dalam ekologi, dengan cara memperlakukan lingkungan sebagaimana layaknya manusia. Lingkungan harus dibeikan hakhaknya, seperti hak hidup dan hak untuk berkembang. Tidak boleh ada diskriminasi perlakuan antara lingkungan dengan manusia. Apalagi merampas hak-hak lingkungan. Kita harus menciptakan hidup yang berkeadilan bukan berkedhaliman.

c. Prinsip Demokrasi (al-Dimukratiyah).

Demokratisasi dalam ranah lingkungan hidup, yaitu membangun suatu kesadaran masyarakat akan pentingnya lingkungan dalam menetapkan keputusan atau kebijakan lingkungan. Karena pada prinsipnya manusia bagian kecil dari lingkungan, ia hidup untuk memelihara dan melestarikan lingkungan, dan konsekwensinya kebijakan yang dikeluarkan adalah kebijakan yang pro-lingkungan.

Manusia dalam hal ini pemerintah dikatakan tidak prolingkungan, apabila memutuskan suatu kebijakan hanya memedulikan kepentingan manusia tanpa peduli terhadap kepentingan lingkungan. Pemerintah yang demokratis dalam hubungannya dengan ekologi, menindak pelaku pengrusakan lingkungan, dan menerapkan program reboisasi serta pemeliharaan terhadap flora dan faona. 
d. Prinsip Integritas Moral.

Dalam upaya menjaga dan melestarikan lingkungan, perlu adanya sinergisitas setiap elemen masyarakat, Dalam arti tidak hanya pemerintah yang bertanggung jawab terhadap lingkungan, akan tetapi seluruh masyarakat tanpa terkecuali. Mereka bersama-sama menggalakkan program cinta lingkungan, seperti reboisasi, penghijauan, tebang pilih dan lain-lain.

Jika hanya pemerintah yang melakukan penjagaan terhadap lingkungan tanpa dukungan penuh dari masyarakat, maka keinginan pemerintah akan sia-sia tanpa hasil. Pada satu pihak pemerintah menjaga, sementara pihak lain masyarakat merusak. Untuk itu pemerintah harus melibatkan semua elemen guna menjaga kelestarian lingkungan hidup.

Melibatkan masyarakat dalam upaya menjaga kelestarian lingkungan, terlebih dahulu harus memberikan pemahaman baru dan penyadaran dari pemerintah terhadap masyarakat akan pentingnya menjaga lingkungan hidup. Jika pemerintah dan masyarakat sinergis menjaga lingkungan, bisa dipastikan program itu akan berjalan lancar sesuai harapan.

\section{Mengupayakan fiqh lingkungan anti-diskriminatif}

Fiqh masih diskriminasi terhadap lingkungan hidup selain manusia. Manusia mendapat tempat yang sangat tinggi dalam pola intraksi kehidupan. Sementara mahluk hidup lainnya (lingkungan) tidak mendapatkan perhatian berarti, terlebih mahluk lain yang tidak muhtaram. Manusia diakui sebagai mahluk paling sempurna dan mulya ketimbang mahluk lainnya. Hal ini karena manusia memiliki akal budi dan postur tubuh sempurna. Sementara mahluk lainnya tidak memiliki akal budi dan postur tubuh seperti manusia. Maka manusia dipandang memiliki otoritas menggunakan seluruh sumber daya alam.

Pemeliharaan dan perlindungan terhadap flora dan fauna masih tebang pilih. Misalnya orang ihram dilarang memotong atau mencabut pohon yang tumbuh sendiri dan dibolehkan untuk pohon yang ditanam oleh manusia. Padahal pada prinsipnya keduanya tidaklah berbeda. Ia sama-sama ciptaan Allah, dipelihara dan dijaga Allah. Tumbuh dan berkembang di atas bumi Allah. Seharusnya keduanya mendapatkan perlakuan hukum sama dari manusia, tanpa ada diskriminasi.

Fiqh masih membedakan antara muhtaram dan ghairu muhtaram. Binatang muhtaram harus di jaga dan pelihara oleh manusia. Ia tidak boleh diganggu atau dibunuh tanpa alasan yang dibenarkan oleh syara'.

$154 \mid$ JURNAL LISAN AL-HAL 
Berbeda dengan binatang yang tidak dimulyakan oleh syara'. Binatang ini boleh dibunuh, bahkan kalau binatang itu binatang buas, disunnahkan untuk membunuhnya.

Seharusnya fiqh tidak membeda-bedakan binatang satu dengan lainnya, sebab semuanya bagian dari mahluk tuhan. Ia harus kita jaga, kita pelihara dengan belaian cinta dan kasih sayang. Binatang-binatang itu kita perlakukan dengan baik, dan kita pelihara dengan baik pula. Jangan hanya memelihara binatang yang bisa dimanfaatkan, lalu mengabaikan binatang yang tidak bermanfaat bagi dirinya.

Manusia hendaknya tidak mengganggu apalagi membinasakan mahluk tuhan dimuka bumi, tanpa alasan yang dibenarkan oleh syara'. Seluruh mahluk mempunyai hak-hak yang harus dilindungi oleh manusia. Hak hidup dan hak berkembang sesuai dengan sunnatullah juga dimiliki oleh mahluk selain manusia. Allah menciptakan tidaklah sia-sia, atau main-main tanpa tujuan. Seluruh ciptaan Allah mengandung hikmah yang sangat besar bagi kehidupan. Ia hamba Allah yang setiap saat senantiasa bertasbih kepada Allah.

\section{Pandangan Fiqh Terhadap Harmonisasi Lingkungan.}

Seperti yang telah peneliti ungkapkan di atas, bahwa fiqh peduli atau ramah lingkungan sejak abad kedua puluh. Bahkan disa dikatakan kepedulian fiqh terhadap lingkungan seiring dengan datangnya agama islam. Sebab fiqh merupakan kepanjangan tangan dari ajaran agama islam, yakni al-Qur'an dan al-hadist. Dalam al-Qur'an tidak ditemukan ajaran yang mengarah pada tindakan distruktif kepada lingkungan. Al-Qur'an mengutuk segala bentuk tindakan pengrusakan pada lingkungan.

Dalam sejarah, tidak ditemukan bahwa Nabi dan para sahabat pernah melakukan pengrusakan terhadap lingkungan. Justru Nabi datang untuk menyelamatkan lingkungan hidup. Beliau memberikan aturan dalam peperangan, seperti tentara islam dilarang membunuh anak-anak, perempuan,binatang dan membakar pohon. Dan dalam hadist Rasul pernah menetapkan suatu tempat di Baqi' Madinah, sebagai hutan lindung. a. Ekomederatisme Fiqh.

Fiqh punya pandangan berbeda dengan pandangan anthroposentrisme, biosentrisme, dan ekofeminisme, dalam hubungan dengan lingkungan. Pandangan antroposentrisme yaitu suatu pandangan yang berpusat pada manusia. Wilayah moral hanya khusus pada manusia, tidak untuk mahluk selain manusia. Segala apa yang tersedia di dunia ini milik manusia. Seluruhnya harus ditundukkan dan dikuasai demi memenuhi hajad hidupnya. Lingkungan akan 
dihargai jika mengandung manfaat bagi manusia, sebaliknya jika tidak bermanfaat akan dibiarkan, bahkan kerapkali dirusak.

Pandangan biosentrisme yaitu suatu pandangan yang berpusat pada seluruh mahluk hidup. Pandangan ini meluaskan ruang jemahan etika. Dimana etika tidak hanya untuk manusia, tapi untuk seluruh mahluk hidup. Pandangan ini masih belum menghargai terhadap lingkungan secara umum. Ia hanya menghargai mahluk hidup. Manusia dipandang sama derajadnya dengan mahluk hidup lainnya.

Pandangan ekosentrisme yaitu suatu pandangan yang berpusat terhadap lingkungan secara keseluruhanyang meliputi: biotik dan abiotik. Lingkungan dihargai karena memiliki nilai dan hak-hak pada dirinya. Lingkungan dikatakan punya hak-hak sebagaimana manusia. Pandangan ini juga menyamakan kedudukan manusia dengan lingkungannya.

Sementara pandangan ekofemisme yaitu suatu pandangan yang berpusat pada lingkungan secara keseluruhan. Penekanannya pada aspek persamaan derajad manusia dan lingkungan serta kebebasan lingkungan untuk hidup dan berkembang. Pandangan ini hampir sama dengan pandangan ekosentrisme. Perbedaannya, ekosentrisme memelihara dan melestarikan lingkungan karena aspek nilai pada diri lingkungan. Sementara ekofemenisme lebih memperhitungkan aspek kasih sayang dan cinta pada lingkungan.

Fiqh punya pandangan ekomoderatisme yaitu pandangan moderat, tidak ekstrim dan tidak leberal. Pandangan ini menganggap, bahwa manusia bagian dari lingkungan. Akan tetapi tidak menganggap manusia sama derajadnya dengan lingkungannya (mahluk lainnya). Manusia punya nilai lebih, berkat adanya akal pikiran dan postur tubuh paling sempurna yang dikaruniakan Allah dan tidak dimiliki mahluk lainnya. Manusia mendapat derajad paling tinggi dan paling sempurna di antara mahluk-mahluk lainnya. Lingkungan sebagai ciptaan Allah harus dipelihara dan dilestarikan. Manusia boleh memanfaatkannya untuk memenui hajad hidupnya, asal tidak melebihi kadar kebutuhan (haad al-kifayah).

b. Fardhu 'ain menjaga lingkungan.

Manusia bagian terkecil dari lingkungan hidupnya. Ia sangat bergantung terhadap lingkungannya. Lingkungan yang ditempati manusia sangat menentukan terhadap kualitas hidupnya. Jika lngkungan yang ita tempati kondusif, maka kualitas hidup semakin baik. Sebaliknya, jika lingkungan kita tidak kondusif, maka kualitas hidup kita semakin terpuruk bahkan bencana selalu mengancam 
hidup kita.

Dalam menjaga lingkungan hukumnya wajib/fardu 'ain. Menurut hemat kami, menjaga lingkungan hidup hukumnya fardu 'ain. Yakni seluruh umat manusia (mukallaf) dikenahi beban taklif menjaga dan melestarikan lingkungan hidup tampa terkecuali. Pendapat ini didukung dengan dasarnash dan maslahah.

Pertama, Allah senantiasa mewanti-wanti kepada umat manusia, agar tidak melakuakn kerusakan dimuka bumi (di darat dan di laut). Tapi kenyatannya kerusakan itu di sebabkan oleh tangantangan jahil manusia. Dan seharusnya manusialah yang harus bertanggung jawab atas semua kerusakan yang terjad di duna ini. Keusakan yang berhubungan langsung dengan manusia diterangkan dalam surat Ar-Rum : 41.

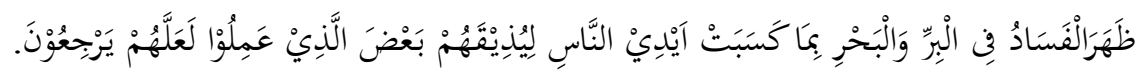

"Telah nampak kerusakan di darat dan di laut disebabkan karena perbuatan tangan manusia, supaya Allah merasakan kepada mereka sebagian dari (akibat) perbuatan mereka, agar mereka kembali ke jalan yang benar."

Ayat ini sekalipun secara dhahir, kalam khabar (bukan insya'), bisa di orientasikan kepada makna insya' dalam arti ijab. Sebab ayat di atas tidaklah berdiri sendiri, akan tetapi masih banyak ayat-ayat lain yang mendukung atas makna ijab (kewajiban). Seperti dalam surat alA'raf:56,

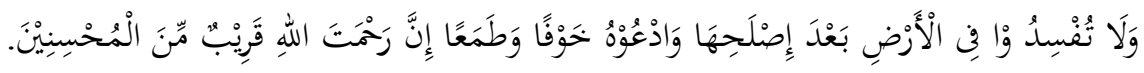

"dan janganlah kamu membuat kerusakan di muka bumi, sesudah (Allah) memperbaikinya dan berdoalah kepada-Nya dengan rasa takut (tidak akan diterima) dan harapan (akan dikabulkan). Sesungguhnya rahmat Allah amat dekat kepada orang-orang yang berbuat baik."

Kata kunci ayat diatas yaitu, wala tufsidu fil al-ardhi ba'da ishlahiha (dan janganlah kamu membuat kerusakan di muka bumi, sesudah Allah memperbaikinya). Ayat di atas juga ditopang oleh ayat berikutnya yang berorientasi terhadap danpak negatif dari pengrusakan (siksa), yaitu:

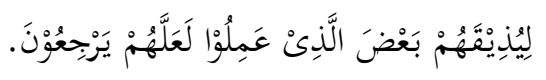


"Supaya Allahmerasakan kepada mereka sebagian dari (akibat) perbuatan mereka, agar mereka kembali kejalan yang benar."

Di antara ayat-ayat yang menunjukkan wajib adalah ayat itu diiringi dengan ancaman siksa. Sekalipun redaksi ayat itu tidak berbentuk perintah atau larangan. Ayat di atas memiliki pengertian, manusia dilarang melakukan tindakan pengrusakan terhadap alam baik didarat maupun dilautan.

Maksud ayat pengrusakan di atas, di jelaskan oleh allah dalam surat al-Baqaroh ayat 205,

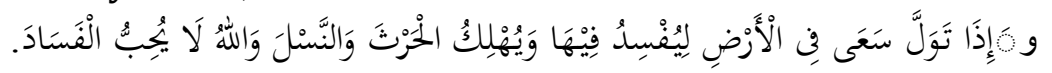

"dan apabila ia berpaling (dari kamu), ia berjalan di bumi untuk mengadakan kerusakan padanya, dan merusak tanam-tanaman dan binatang ternak, dan Allah tidak menyukai kebinasaan."

Kedua, melihat kenyataan global, keharusan peduli terhadap lingkungan di dukung oleh realitas dunia. Bahwa krisis lingkungan hidup menjadi ancaman serius bagi seluruh makhluk hidup di dunia. Lapisan ozon telah menganga lebar akibat emisi rumah kaca. Radiasi ultra violet dengan leluasa menembus bumi. Akibatnya sekitar lima belas gunung es meleleh di kutub utara. Maka pemanasan global menjadi realitas yang mengancam kehidupan dunia. Oleh sebab itu perlindungan dan pelestarian lingkungan hidup menjadi hal yang sangat urgen demi terciptanya harmoni dunia.

Maka tidak ada alasan untuk menyangkal tentang hukum wajib 'ain perintah menjaga lingkungan hidup. Dalam ushul fiqh dikatakan, la dharara wala dirara (tidak boleh membuaut mudharat kepada dirinya mauoun pada orang lain). Kaidah ini seharusnya kita kembangkan wilayah jangkauannya terhadap lingkungan hidup. Larangan membuat mudharat tidak hanya pada dirinya orang lain, akan tetapi berbuat mudharat pada lingkunganpun juga dilarang.

Menjaga keselamatan jiwa (hifdhu an-nafs) takkan bisa terwujud kalau lignkungan tdak terjaga. Dalam qaidah fiqh dikatakan, malayatimmu al-wajib illa bihi fahuwa wajib (suatu kewajiban (perbuatan) yang tidak bisa sempurnah tanpa perbuatan lain, maka perbuatan itu hukumnya juga wajib). Dari qaidah ini bisa dipahami bahwa menjaga lingkungan hukumnya wajib demi terwujudnya keselamatan jiwa.

Qaidah di atas selaras dengan qaida berikutnya yaitu : Alwashail hukmul maqasid (perkara hukumnya sama dengan tujuan). Jika tujuan tu wajib, maka perantara hukumnya wajib pula. Karena 
menjaga kulliyatu al-khams hukumnya wajib, maka wajib pula menjaga lingkungan yang menjadi perantara tercapainya tujuan itu.

c. Hak Pemanfaatan Manusia.

Seluruh sumber daya alam yang tersedia didunia ini untuk kepentingan manusia. Allah menundukkan bumi beserta isinya, lautan beserta isinya dan langit beserta planet-planetnya untuk kemaslahatn manusia. Tetapi manusia tidak bertindak sewenang-wenang terhadap lingkungan. Segala bentuk ekspolitatif yang mengarah pada tindakan destruktif sangat dimurka oleh Allah. Manusia punya hak hanya untuk memanfaatkannya, itupun tidak lebih dari kadar kebutuhannya (hadd al-kifayah).

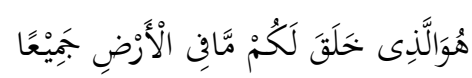

"Dialah Allah, yang menjadikan segala yang ada di bumi untuk kam" Ayat ini menjelaskan bahwa segala apa yang tersedia di bumi untuk kepentingan manusia. Tapi manusia tidak boleh berbuat sewenang-wenang atau melampaui batas, seperti mengisploitasi sumber daya alam. Manusia memiliki hak atau dengan kata lain di izinkan oleh Allah hanya sebatas memanfaatkan. Sebab lam dalam ayat diatas bukan bemakna li al-milk (memiliki) akan tetapi bermakna li at-tanfi (memanfaatkan).

Dari itu sekalipun segala sumber daya alam disediakan untuk manusia, manusia tidak sebagai tuan pemilik. Pemiliknya adalah Allay yang maha pencipta. Manusia hanya bisa memanfaatkan sesuai dengan ketentuan pemilik (Allah) dan tidak melebihi kadar kebutuhan (had al-kifayah).

d. Tidak ada sanksi dan larangan yang jelas terhadap pelanggar.

Dalam logika hukum ada adigium. "setiap ada hukum pasti ada pelanggaran, jika ada pelanggaran harus ada sanksi." Demikian juga dalam fiqih lingkungan seharusnya ada larangan tegas disamping perintah, dan harus ada sanksi tegas bagi yang melanggar peraturan itu sebagai konsekwensi logisnya.

Tapi pada kenyataannya fiqih lingkungan masih belum bisa memberikan sanksi yang tegas bagi pelanggar hukum lingkungan. Fiqih lingkungan hanya memerintah agar kita menjaga lingkungan dan melarang merusak lingkungan. Belum ada sanksi tegas dan pasti yang bisa kita terapkan dalam kehidupan. Untuk itu kiranya pemerintah yang bertanggung jawab (tauzi' sulthany) memberikan sanksi kepada pelanggar kelestarian lingkungan hidup. Sanksi yang diberlakukan pemerintah tentunya harus sesuai dengan bentuk pelanggaran dan 
dampaknya terhadap lingkungan.

\section{Simpulan}

Bertolak dari rumusan masalah dan hasil penelitian yang telah peneliti paparkan serta analisa yang telah peueliti lakukan, maka peneliti dapat mernngambil kesirnpulan sebagai berikut:

1. Fiqh memiliki konsepsi harmonisasi lingkungan. Konsepsi ini dapat peneliti simpulkan menjadi tiga kategori yait.i; a) konsepsi kesucian air batu dan tanah, b) konsepsi udara bersih dari polusi, dan c) konsepsi pelestarain flora dan fauna.

2. Fiqh mempunyai pandangan ekomoderatisme terhadap lingkungan. Yaitu pandangan yang tidak terlalu ekstrim dan liberal (tawassuth) dalam hubungannya dengan lingkungan. dengan kata lain, manusia memiliki derajat lebih tinggi daripada mahluk lainnya Akan tetapi manusia berkewajiban (wajib 'ain) untuk menj 19a huk-hak lingkungan, seperti hak hidup dan berkembang sesuai dengai sunnatullah. Fiqh membe-ikan kebebasan pada manusia untuk memanfaatkan suber caya alam yang telah disediakan oleh Allah. Pemanfaatan tidak boleh meleb.hi batas kebutul.an (hadd alkifayahi).

\section{DAFTAR PUSTAKA}

Abdillah, Mujiono,Agama Ramah Lingkungan Perspektif Al-Qur'an, Paramadina, Cet II, Jakarta, 2001.

Abdillah, Mujiono, MA, Dr. Agama Ramah Lingkungan Perspektif Al-Qur'an, Jakarta: Paramadina. 2001.

Abudin, Nata, Metodologi Stull; Islam, Jakarta: Raja Grafindo Persada, 1998. AI-Bajuriy, Ibrahim, Hasyiyalt Al-Bajuriy 'Ala Inbni Qosyim, al-Hidayah, 1994.

Akhyar, Salman, Biologi Untuk SMA kelas X, Grafindo Media Pertama, 2005. Al-Husny, Faidullah, Fathuor Rohman, Diponogoro, Cet IT, 1997.

Al-Husny, Faidullah, Fathur Rahman Lithalibi Ayati AI-Qur'al, Rosdakarya, Jember, 2005.

Al-Jaziry, Abd Rahman, Kitabu al-Fiqh Ala Madzahibu al-Arba'ah, Dar alFikr, 1984.

Al-Jurjany, Ahmad. Hikmatu At-Tasyri' Wa Falsafatuhu, al-Hidayah, 1897.

al-Khatib, As-Sarbiny . Mughni Af-Muhtaj, Dar Al-Fikr, 1986.

Al-Mandhur, Lisanu Al-Arab, Beirut, 1987.

$160 \mid$ JURNAL LISAN AL-HAL 
Asmuni, Yusran, Pertumbuhan Dan Perkcmbangan Berfikir Dalam Islam, al- Ikhlas, 1994.

Keraf, A. Sonny. Etika Lingkungan. PT Kompas Media Nusantara, cet IV, 2005.

Qardhawi, Yusuf, Dr., Peran Nilai Dan Moral Dalam Perekonomian Islam, Raobani Press, Jakarta, 2004.

Rahmat (ed.), Imdadun, M., Kritik Nalar Fiqh: Transformasi Paradigma Bahtsul AlMasa'il, Lakpesdam, cet Islam, 2002.

Ridha, Rasid. Sayyid Muhammad, Tafsir Al-Qur'an Al-Hakim (Tafsir al-Manar), Dar Al Ma'rilah, Beirut, 1998.

Rozy, Fahkrur, Tafsir Al-Kabir, Dar Al-Kutuby Al-Ilmiyyah, Teheran., 1987.

Shihab, M. Quraish, Tafsir Al-misbah, Jakarta: Lentera Hati, 2005.

Shihab, M. Quraisy, Menabur Pesan Ilahi, Mizan, Bandung, 2005.

Shihab, M. Quraiys, Tafsir Al-Misbah, Lentera Hati, Jakarta, Cet II, 2006.

Shihab, Quraisy. Membumika Al-Qur'an, Mizan, Bandung, Cet IV, 2005.

Shihab, Umar, MA. Prof Dr., Kontekstualitas Al-Qur'an, Penamadani, Jakarta, 2003

Soemarwoto, Otto, Lingkungan Hidup dan Pembangunan, Karya Unepress, Cet, IX, 2005.

Sumaryono, E., Hermeneutika; Sebuah Metode Filsafat, Yogyakarta: Kanisius, 1995.

Suprayogo, Imam dan Tobroni, Metodologi Penelitian Sosial-Agama, Bandung : PT. Remaja Rosda Karya, 2001.

Suryani (ed.), Moh., Lingkungan: Sumberdaya Alam Dan Kependudukan Dalam Pembangunan, VI Press, Jakarta, 1987.

Syihab, M. Qurasy, Menabur Pesan Iiahi, Lentera Hati, Jakarta Selatan., Cet.l. April. 2006.

Tim Penyususun, Tuhfatur Rohabah: Taya Jawab Masalah Agama, PP. al-Falah Ploso Kediri, 1998.

Umar Asy-Syathiry, Ahmad. Al-Yaqutu An-Nafis, al-Hidayah. Surabaya, 2003.

Wahbah az-Zuhaily, Dr. Ushul Fiqh al-Islamy, Beirut, 2005.

Yafie, Ali. Menggagas Fiqh Sosial, Mizan, Cet I, Bandung 1994.

Yazid, Abu LL.M, Dr, Islam Akomudatif, Yogyakarta: LKiS, Cet 1, 2004.

Zakariyah Al-Anshariy, Abi Yahya. Fathul Wahhab, al-Hidayah. Semarang. 1965. 


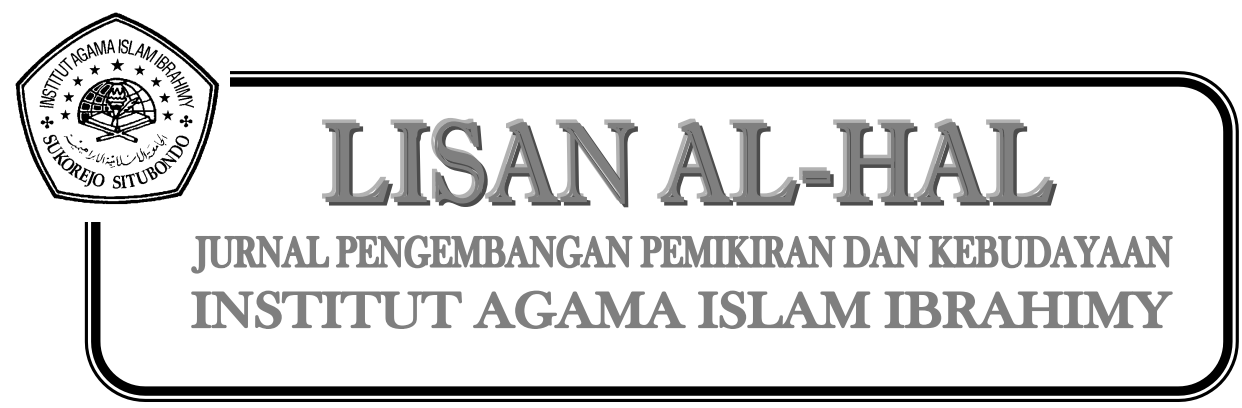

162 JURNAL LISAN AL-HAL 